\title{
A COMPREENSÃO DO GÊNERO NÃO-EXPLICITADO DA AUTORIA DE UM TEXTO: UM EXPERIMENTO EM SALA DE AULA
}

\author{
Comprehension of the Unmarked Gender of the Authorship of a Text: An \\ Experiment in the Classroom
}

\section{Lucianne Christina Fasolo Normândia MOREIRA ${ }^{1}$, Celin-UFPR}

RESUMO: Este artigo discute um experimento realizado em duas turmas de Inglês PréIntermediário do Celin (Centro de Línguas e Interculturalidade) da UFPR, com o intuito de verificar a influência dos estereótipos de gênero na compreensão e atribuição de um gênero à autoria de um texto no qual não houvesse marcas explícitas para fácil direcionamento da interpretação dos alunos. Utilizando-se uma base teórica acerca das manifestações do gênero na língua e sua íntima relação com as concepções presentes na cultura dos falantes, formulou-se a hipótese de que, embora marcas evidentes de gênero não estivessem presentes no texto, os alunos seriam capazes de atribuir um gênero à autoria ao fazerem a leitura com base nas concepções de gênero internalizadas durante o processo de socialização.

PALAVRAS-CHAVE: Concepções de gênero; Autoria; Compreensão de Texto.

\begin{abstract}
This article proposes to discuss an experiment made with two PreIntermediate English groups at Celin (Centro de Línguas e Interculturalidade) at UFPR, which had the purpose of verifying the influence of gender stereotypes in the comprehension and attribution of a gender to the authorship of a text in which there were no explicit marks of gender, which might easily lead the students' interpretation. By making use of a theoretic base on the manifestations of gender in language and its close relation to the conceptions found in speakers' culture, a primary hypothesis has been made that, although no evident marks of gender might be found in the text, students would have little difficulty in attributing a gender to the author of the text by means of reading through gender concepts internalized during the process of socialization.
\end{abstract}

KEY WORDS: Gender concepts; Authorship; Text Comprehension.

\footnotetext{
${ }^{1}$ Professora de Língua Inglesa no Celin - UFPR. Graduanda em Letras pela UFPR.
} 


\section{INTRODUÇÃO}

O presente artigo é fruto de um experimento realizado com alunos de duas turmas de Inglês nível Pré-Intermediário I no Celin (Centro de Línguas e Interculturalidade). A motivação para tal experimento surgiu com minha experiência de professora na instituição mencionada. Durante os quatro semestres de trabalho como professora de inglês no Celin, um de meus principais interesses tem sido o trabalho com a leitura e compreensão de textos autênticos, levados à sala de aula em forma de atividades complementares ao uso do material didático adotado pela área de Inglês no Celin ${ }^{2}$. Neste trabalho, em especial, tenho o costume de observar como se dá a interpretação da autoria do texto pelos alunos, e tenho notado um fato que considero interessante. Em atividades de leitura e compreensão textual, é comum ouvir dos alunos referências à pessoa autora do texto (positivas ou não, mas precisas) como he ou she (ele e ela, em inglês) - mesmo que o texto em questão não revele o gênero da autoria explicitamente, o que com frequência é o caso. Uma vez despertado o meu interesse, decidi realizar um pequeno experimento para verificar como os alunos compreendiam o gênero da autoria em um texto aparentemente "neutro", ou seja, sem marcas evidentes que pudessem direcionar a interpretação com facilidade.

Como defendido por diversos pesquisadores como Clarissa Menezes Jordão (2007), a língua não é algo que pode ser dissociado da cultura dentro da qual ela é utilizada. Ela não é um código "puro", imune à influência dos valores culturais internalizados pelos falantes. Em uma análise linguística, é possível observar como as concepções sociais se encontram impregnadas na língua em seus diversos níveis, bem como são sustentadas por ela. Com relação às concepções de gênero, não é diferente. Linguistas e teóricas feministas como Julia Penelope (1990) argumentam que as concepções de gênero - afirmações e expectativas culturais acerca do comportamento de homens e mulheres - se encontram refletidos na língua utilizada por falantes cuja cultura mantém tais concepções, tanto ao nível semântico-lexical quanto ao nível fonológico, sintático e discursivo. Sendo assim, uma cultura patriarcal ou que se baseie em concepções de gênero (que tomam o homem como representante universal da humanidade e que, por exemplo, definem a mulher como

\footnotetext{
${ }^{2}$ O material referido é a série de livros New American Inside Out, escrita por Sue Kay e Vaughan Jones e adaptada por Catherine Smith e Peter Maggs, publicada pela editora Macmillan.
} 
maternal e frívola e o homem como competitivo e racional) de fato impregna a língua com as concepções sociais dominantes, determinando sua classificação como língua patriarcal.

Portanto, seria pouco provável que as concepções de gênero não exercessem influência sobre a interpretação do gênero da autoria de um texto. Mesmo que não houvesse marcas ou referências explícitas ao gênero, seria de se esperar que os leitores fossem capazes de atribuir um gênero à autoria por via da utilização das concepções de gênero (internalizadas) como meio de análise do texto. A fim de verificar esta hipótese, realizei um experimento de compreensão textual com alunos de inglês no Celin. Uma vez que concepções de gênero estão presentes tanto na cultura brasileira quanto em culturas de língua inglesa, o fato de que a língua materna dos alunos não é o inglês não foi considerado um fator que alterasse a interpretação do gênero da autoria do texto. Os resultados do experimento foram primeiramente apresentados na forma de um estudo de cunho etnográfico para a disciplina Cultura e Ensino de Língua Estrangeira Moderna na Escola, ministrada pela Prof. Dra. Mariza Riva de Almeida no segundo semestre de 2011. No presente artigo, a base teórica, a metodolologia, os resultados e as conclusões do experimento serão apresentados novamente. Porém, por falta de oportunidade não serão discutidas estratégias para trabalho com concepções de gênero em sala de aula. ${ }^{3}$

\section{NA TEORIA: O QUE É O GÊNERO, E COMO SE MANIFESTA NA LÍNGUA?}

É possível compreender, através de uma análise inicial, que a cultura é permeada em seus diversos níveis por concepções acerca dos comportamentos/ações/atitudes "normais" de homens e de mulheres, entre os quais o senso comum afirma haver diferenças marcantes e imutáveis. Tais concepções de fato delimitam a posição social a ser ocupada por homens e mulheres; ao mesmo tempo, elas mascaram as motivações por trás da instituição dessa posição social através da naturalização da mesma, como a teórica

\footnotetext{
${ }^{3}$ É importante ressaltar que o objetivo de discutir possíveis estratégias para lidar com as concepções de gênero em sala de aula, embora extremamente relavante tanto para os estudos de gênero como para o ensino de línguas, acabaria por se mostrar muito ambicioso para ser desenvolvido no momento. Tal objetivo de fato mereceria um artigo inteiramente dedicado a ele, e não apenas uma breve seção ao final deste artigo. Esperase, no entanto, que a discussão de modelos para o trabalho com concepções de gênero ocorra posteriormente, inspirada pelos resultados do experimento relatado neste artigo, seja na forma de outro artigo de minha autoria ou não.
} 
Monique Wittig (1992) afirma em um ensaio ${ }^{4}$. Assim, seguindo as noções presentes no senso comum, conclui-se que mulheres são emotivas, "sonhadoras", instáveis e triviais - o que supostamente justificaria o fato de não serem fequentemente escolhidas para ocupar cargos elevados, por exemplo; por sua vez, homens são sérios, racionais, confiáveis e competitivos - portanto, justificando o fato de serem sumariamente considerados aptos a exercer cargos "exigentes" e de prestígio. No entanto, longe de serem "naturais" ou baseadas em fatos concretos, essas concepções sobre homens e mulheres são na realidade fruto de construções sociais acerca do que significa ser homem e ser mulher na sociedade. A essas construções sociais se atribui o conceito de gênero, um termo que a socióloga feminista Denise Thompson (2001) observa ter sido originalmente cunhado para lidar com a noção de que as supostas diferenças entre os sexos são socialmente construídas ao invés de naturais, e não se baseiam no sexo biológico (p. 74) ${ }^{5}$.

Diversas pesquisadoras feministas já escreveram sobre as concepções de gênero, e a íntima relação entre elas e a manutenção e permanência de uma estrutura social injusta baseada em privilégio e opressão. A teórica Marilyn Frye (1983) observa em um ensaio que o sexismo - a noção de que o sexo de um indivíduo é um fator relevante para privilegiá-lo/discriminá-lo - decorre da divisão compulsória de uma população entre dois gêneros distintos, cujos comportamentos e ações são rigidamente descritos e delimitados (p. 19). Segundo Frye, a sociedade exige a identificação do gênero dos indivíduos

\footnotetext{
${ }^{4}$ WITTIG, Monique. The Category of Sex. In: The Straight Mind and Other Essays. Boston: Beacon, 1992, p. 2.

${ }^{5} \mathrm{O}$ conceito de gênero, conforme observado por diversas feministas, apresenta graves problemas na sua definição. Segundo Thompson (2001), esse conceito é frequentemente utilizado de forma equivocada ou ambígua, o que o distancia do seu propósito inicial e obscurece o seu significado, a tal ponto que se pode falar em gênero para remeter a qualquer coisa (p. 71-72). Uma das conceitualizações consideradas problemáticas é a proveniente da teoria queer, dentro da qual o gênero é definido como performativo. Segundo essa teoria, que possui suas raízes na teoria pós-moderna, as identidades sexuais são fluidas e múltiplas; e, dessa maneira, categorias sociais como 'mulher' e 'homem' são vistas como artificiais, pouco relevantes e passíveis de serem "transgredidas" por meio da performance de identidades sexuais que supostamente desviam de tais categorias. Wilkinson e Kitzinger (1997) observam que, embora atraente por sua promessa de mudança social e destruição de categorias binárias, a teoria queer é de fato movida pelo conservadorismo, ao mostrar-se oposta a qualquer tentativa de análise crítica do impacto social de práticas ditas "transgressoras" (p. 375-382). Jeffreys (2003) também comenta que a teoria queer tem recebido críticas por dificultar a ação social devido à desconstrução de identidades e enfraquecimento dos laços entre indivíduos, bem como que é apontada como responsável por perpetuar a categoria binária feminilidade/masculinidade ao insistir na performance do gênero ao invés do seu desmantelamento (p. 3940). Sendo assim, conceitos como o de gênero como performance não se mostram adequados ao presente artigo, que propõe uma análise da observação prática da utilização, na compreensão textual, de concepções socialmente veiculadas acerca das categorias 'homem' e 'mulher'. Como base teórica deste trabalho, foi então selecionado um conjunto de análises especificamente feministas sobre o gênero, que sustentassem a sua proposta de análise.
} 
obrigatoriamente através do comportamento social, constituído de diversos padrões comportamentais a ser seguidos por homens e mulheres; como parte complementar deste, no entanto, Frye também menciona o comportamento linguístico (1983, p. 19-21). Em outras palavras, a identificação do gênero se dá não somente através dos comportamentos e ações dos indivíduos, mas também através da comunicação oral e escrita.

Nesse sentido, não se entende a língua como um código neutro, ou algo "puro" e por consequência imune a interações com a cultura de seus falantes. Pelo contrário: as concepções sociais permeiam a língua, e até mesmo estabelecem os limites do que pode ou não ser dito - ou do que é possível dizer. Em seu livro sobre as manifestações linguísticas do sexismo, a linguista feminista Julia Penelope (1990) discorre sobre a influência profunda que a cultura exerce sobre a língua, que se manifesta nas escolhas vocabulares e na própria estruturação do pensamento. Na visão da pesquisadora, a estrutura semântica da língua, moldada pelos valores culturais, constitui um esquema conceitual imposto aos falantes.

\begin{abstract}
A cultura na qual vivemos determina em muito a maneira como categorizamos o mundo e compreendemos as coisas que percebemos porque é ela que fornece o vocabulário do qual escolhemos nossas palavras, incluindo as informações acerca de que escolhas vocabulares são os termos preferíveis para falar sobre certas situações e eventos. A estrutura semântica de uma língua pode ser pensada como uma grade, um esquema conceitual que a cultura dessa língua impõe sobre a experiência e as percepções de seus falantes. (p. 46, tradução minha) ${ }^{6}$
\end{abstract}

As concepções de gênero são analisadas por Penelope como integrantes do esquema conceitual da língua. A fim de explicar como se dá a difusão destas concepções em sociedade, a linguista se utiliza da noção de universo de discurso. Um universo de discurso, ela escreve, consiste em "um modelo cultural da realidade que as pessoas utilizam diariamente para decidir como agir e o que dizer em contextos específicos" (p. 36, tradução minha ${ }^{7}$ ). Tal universo de discurso de fato equivale à realidade consensual; e, portanto, este modelo fornece aos falantes de uma língua uma concepção preestabelecida do mundo, que é aceita por eles como a representação da realidade em si. Obviamente, um

\footnotetext{
${ }^{6}$ Trecho original: "The culture we live in determines, to a large extent, how we categorize the world and understand the things we perceive because it is culture that provides the vocabulary from which we choose our words, including the information about which vocabulary choices are the preferred terms for talking about certain situations and events. The semantic structure of a language can be thought of as a grid, a conceptual frame, that its culture imposes on the experience and perceptions of its speakers."

${ }^{7}$ Trecho original: "What I'm calling a 'universe of discourse' is a cultural model of reality that people use daily to decide how to act and how to say in specific contexts."
} 
universo de discurso não é um sistema fechado e imutável, como assinala Penelope; no entanto, há aspectos dele que se encontram cristalizados, e resistem fortemente a modificações. Neste sentido, um contexto social novo ou diferente tende a ser mais frequentemente "encaixado" no paradigma conceitual existente, e visto através de uma perspectiva já tradicional em vez de servir de motivação para a reestruturação do paradigma conceitual em si (PENELOPE, 1990, p. 37). Pode-se dizer que as concepções de gênero são um dos aspectos mais resistentes a modificações, e estas são o cerne do que Penelope denomina universo de discurso patriarcal (patriarchal universe of discourse, ou $P U D$, no original) - um paradigma conceitual que parece transcender barreiras nacionais e culturais sem sofrer grandes modificações na sua essência (p. xxvii) ${ }^{8}$. Segundo Penelope, que escreve mais especificamente sobre a língua inglesa mas que também estabelece comparações com outras línguas/culturas como o chinês, o japonês e o Dyirbal (uma língua tribal), o universo de discurso patriarcal "divide o mundo em duas esferas desiguais e estereotípicas: uma feminina, a outra masculina; ele descreve essas duas esferas em áreas bem definidas e discretas do vocabulário que nomeiam pessoas, seus comportamentos, atitudes e atividades no mundo" (p. 38, tradução minha ${ }^{9}$ ). A linguista também afirma que essa divisão do mundo em duas esferas "reflete a noção patriarcal de que certos comportamentos e atividades são 'apropriadamente' femininos, enquanto que outros, [os comportamentos e atividades] que os homens optam por perceber como 'importantes', são 'apropriadamente' masculinos" (p. 38, tradução minha ${ }^{10}$ ). Assim, o universo de discurso patriarcal define o que e como a mulher e o homem devem ser, e qual é o comportamento "normal" (leia-se socialmente aceito) de cada um dos gêneros.

De uma forma geral, características humanas tidas como positivas e desejáveis por exemplo, coragem, honestidade, racionalidade, força, constância, controle, poder, entre outras - são atribuídas, no universo de discurso patriarcal, à esfera masculina. À esfera feminina são atribuídas características humanas negativas ou consideravelmente menos valorizadas - indecisão, emotividade, fragilidade, insegurança, dependência, altruísmo,

\footnotetext{
${ }^{8}$ Segundo Penelope, a existência de um universo patriarcal de discurso em funcionamento define uma cultura como patriarcal. E, uma vez que as concepções culturalmente difundidas se refletem na língua, uma cultura patriarcal determina a classificação de uma língua como patriarcal.

${ }^{9}$ Trecho original: "PUD divides the world into two, unequal, stereotypical spheres: one female, the other male; it describes these two spheres in well-defined, discrete areas of the English vocabulary that name people, their behaviors, attitudes, and activities in the world."

${ }^{10}$ Trecho original: "The split reflects the patriarchal idea that specific behaviors and activities are 'properly' female, while others, those men choose to perceive as 'important', are 'properly' male."
} 
maternalidade; estas duas últimas exaltadas apenas de forma abstrata, segundo algumas pesquisadoras feministas. Em um artigo especificamente sobre a língua inglesa, Penelope (1988) escreve: “[o] espaço semântico do inglês está perfeitamente dividido de acordo com estereótipos sociais dos papéis sexuais; mulheres são frágeis, passivas e desonestas, todos atributos negativos, enquanto que homens são fortes, corajosos, honestos e francos, todos atributos positivos" (p. 129, tradução minha ${ }^{11}$ ). De fato, a definição do que é ser homem por sua vez constrói a definição universal do que é ser humano, sendo a definição do que é ser mulher apenas uma particularidade, algo insignificante e desprezível que se localiza abaixo do humano (PENELOPE, 1990, p.49).

Sendo assim, o gênero masculino (juntamente com a gama de termos associados a ele) é compreendido como representante genérico ou "neutro" do ser humano em sua totalidade, enquanto que o gênero feminino deve ser estritamente especificado através da linguagem. É de extrema relevância ressaltar que, como observa Penelope, os termos que especificam o gênero feminino seguem a tendência de adquirir uma conotação pejorativa, negativa, ofensiva ou sexual. Por exemplo, Penelope observa que, no inglês, o termo professional adquire uma conotação sexual e pejorativa quando aplicado a uma mulher, e que termos "neutros" mas denotativos de cargos de prestígio - como doctor, surgeon, e lawyer - são automaticamente compreendidos como referências a membros do gênero masculino, sendo necessário especificar linguisticamente a referência a um membro do gênero feminino (1990, p. 112-113). Da mesma maneira, pode-se observar empiricamente no português que secretária e empregada possuem uma conotação derrogatória ou denotativa de inferioridade socioeconômica que secretário e empregado não possuem. Quanto à marcação por gênero de termos para profissões, Penelope (1988) escreve que a assimetria semântica entre termos supostamente simétricos reflete a assimetria semântica causada pela definição social de papéis sexuais para os gêneros; e que, quando uma mulher tenta abandonar o espaço semântico que a define como objeto sexual, trabalhadora mal (ou sequer) paga e reprodutora, sua transgressão deve ser linguisticamente marcada.

O fato de que precisamos marcar termos ocupacionais por gênero indica que nosso espaço semântico é rigidamente determinado por papéis sexuais culturalmente definidos, e quando uma de nós atravessa a fronteira do espaço que nos é fornecido pelo léxico do inglês, nós nos deslocamos para um espaço

\footnotetext{
11 Trecho original: "The semantic space of English is neatly divided in accordance with social sex-role stereotypes; women are fragile, passive and dishonest, all negative attributes, whereas men are strong, bold, honest and forthright, all positive attributes".
} 
semântico negativo, e acomodações lingüísticas especiais devem ser feitas. (p. 121 , tradução minha) ${ }^{12}$

No entanto, o universo patriarcal de discurso não se manifesta na língua apenas no aspecto semântico-lexical. Como documentado por Penelope (1990), a especificação do gênero em uma língua patriarcal (aquela que reflete e expressa valores, conceitos e suposições de uma cultura controlada por homens) se manifesta em diversos níveis linguísticos. Ao nível fonológico, a fala de homens e a de mulheres possuem diferenças marcantes no que diz respeito à pronúncia, entonação e ênfase; ao nível sintático, a fala de homens e mulheres diferem em termos da presença de estruturas que marcam tais falas como assertivas e submissas ou "polidas", respectivamente. E, em algumas línguas, como o japonês, Penelope observa que a especificação de gênero se manifesta também ao nível morfológico, sendo necessário que falantes do gênero feminino especifiquem seu gênero através do uso de prefixos e sufixos denotativos de sua posição subordinada, ou que evitem termos "assertivos", exclusivos de uso de membros do gênero masculino (p. 79-83).

A pesquisadora Susan Knutson (1988), em um artigo sobre a manifestação do gênero masculino como genérico ou universal principalmente nas línguas inglesa e francesa, apresenta uma visão um tanto semelhante à de Penelope. Uma das diferenças relevantes no discurso das duas pesquisadoras, porém, seria a afirmação de Knutson de que o gênero na linguagem é uma categoria gramatical, mas que sua presença não é "natural" ou inócua como diversos estudiosos afirmaram ao longo da História. Pelo contrário: o gênero linguístico serve o propósito de alçar o masculino à posição de representante universal do ser humano, ao mesmo tempo que exclui o feminino da concepção de humanidade e o marca como excepcional, particular ou não-essencial. Além disso, Knutson afirma que o genérico masculino é a ferramenta através da qual as mulheres são definidas na língua como objetos sexuais (p. 80). À maneira de Penelope, a pesquisadora discorre sobre as manifestações do gênero na língua em seus diversos níveis. No entanto, diferentemente de Penelope, Knutson atribui a presença do genérico masculino na língua a uma característica do tronco lingüístico do Indo-europeu, ao invés de analisar mais profundamente a relação entre concepções de gênero e sua manifestação na língua, relação

\footnotetext{
${ }^{12}$ Trecho original: "That we need to mark occupational terms for gender indicates to me that our semantic space is rigidly determined by culturally defined sex role, and when one of us goes beyond the boundary of the space provided for us by the English lexicon, we move into negative semantic space, and special linguistic accomodations must be made."
} 
esta que não é apenas observada em línguas/culturas ligadas ao Indo-europeu. Assim, a pesquisadora não comenta extensivamente sobre as motivações sociopolíticas por trás da aplicação do genérico masculino, por exemplo, e não discute a razão pela qual uma "visão anti-mulher do mundo" se mostra presente na língua.

\begin{abstract}
Uma assimetria lexical imensa, a existência de predicados marcados por sexo, o uso do masculino como genérico e o gênero masculino da maioria dos termos que denotam agência, que remontam ao Indo-europeu, tudo isso trabalha em conjunto para criar uma visão parcial e anti-mulher do mundo. Isto levou feministas a postular generalizações linguísticas abrangentes como a existência de uma regra semântica que desvaloriza termos utilizados para mulheres e a relegação das mulheres a um "espaço semântico negativo". (p. 77, tradução minha) ${ }^{13}$
\end{abstract}

A linguista Robin Lakoff (1973), em seu artigo em muitos aspectos inovador sobre a linguagem e a posição social da mulher, discute as manifestações da "linguagem das mulheres" especificamente na língua inglesa de forma semelhante a Penelope. Segundo ela, uma variante linguística marcada é imposta às mulheres através da socialização desde a infância, cujo propósito é mantê-las "no seu lugar" (p. 47), entre outras coisas impedindo-lhes de se expressarem de forma confiante e direta e de definirem a si próprias como agentes no âmbito social; além disso, a linguagem utilizada para definir as mulheres também as retrata como seres não-autônomos, meros objetos. Ironicamente, observa Lakoff, o comportamento lingüístico imposto às mulheres por via da socialização é subsequentemente utilizado como evidência da sua incapacidade de expressar-se com clareza e eficiência. Como partes integrantes da "linguagem das mulheres", Lakoff cita alguns recursos linguísticos cuja função é a de tornar a fala menos séria, ou "apropriada a uma dama". Dentre eles, destacam-se escolhas lexicais como a utilização de adjetivos e interjeições que marcam o que está sendo dito como não importante, o emprego de partículas sinalizadoras de "polidez" e o uso de tag questions, que Lakoff analisa como uma estratégia linguística com o objetivo de tornar uma afirmação menos assertiva (p. 53 55). Embora existam estudos que refutem alguns dos seus achados (principalmente no que se refere ao uso das tag questions) e Penelope também teça uma crítica sobre as eventuais

\footnotetext{
13 Trecho original: "Enormous lexical asymmetry, the existence of sex-marked predicates, the use of the masculine as generic and the masculine gender of most agency nouns, stretching back to lndo-European, all work together to create a lop-sided, anti-woman view of the world. This has led feminists to posit farreaching linguistic generalizations such as the existence of a semantic rule which de-valorizes terms for women, and the relegation of women to "negative semantic space."
} 
limitações de sua análise (1990, p. xxi-xxiii), o trabalho de Lakoff permanece uma referência para a construção da análise das particularidades da "linguagem das mulheres" e sua relação com a construção social da "essência feminina" (se apenas por seu caráter pioneiro).

Será compreendido que o efeito geral da "linguagem das mulheres" - que significa tanto a linguagem de uso restrito às mulheres quanto a linguagem estritamente para descrição das mulheres - é isso: ela submerge a identidade pessoal de uma mulher, ao negar-lhe os meios de se expressar de forma confiante, por um lado, e encorajando expressões que sugerem trivialidade de assunto e incerteza acerca dele; e, quando está se discutindo sobre uma mulher, ao tratá-la como um objeto - sexual ou não - mas nunca como uma pessoa séria com visões individuais. Obviamente, outras formas de comportamento na sociedade possuem o mesmo propósito; mas os fenômenos parecem especialmente claros linguisticamente.

O efeito final dessas discrepâncias é o de que o poder é sistematicamente negado às mulheres, com base em que elas não são capazes de mantê-lo, como demonstrado por seu comportamento lingüístico juntamente com outros aspectos do seu comportamento, e a ironia é que as mulheres são levadas a sentir que merecem tal tratamento, por causa de inadequações de sua própria inteligência e/ou educação. Mas na realidade é precisamente porque as mulheres aprenderam suas lições tão bem que elas sofrem tal discriminação subsequente. (LAKOFF, 1973 , p. 48, tradução minha) ${ }^{14}$

Em um ensaio sobre a relação entre o gênero e a formação da subjetividade, Monique Wittig (1992) observa que o gênero na linguagem, embora interpretado por diversos estudiosos como um aspecto inofensivo e abstrato, de fato possui grande influência sobre a interpretação da realidade concreta. "A linguagem deposita feixes da realidade sobre o corpo social, marcando e moldando-o violentamente" (p. 78, tradução minha ${ }^{15}$ ). Assim, a construção social dos sexos como categorias políticas ou "categorias da opressão" se encontra plenamente refletida na língua: o gênero, segundo Wittig, "é o indicador linguístico da oposição política entre os sexos e da dominação das mulheres” (p.

\footnotetext{
${ }^{14}$ Trecho original: "It will be found that the overall effect of 'women's language' - meaning both language restricted in use to women and language descriptive of women alone - is this: it submerges a woman's personal identity, by denying her the means of expressing herself strongly, on the one hand, and encouraging expressions that suggest triviality in subject-matter and uncertainty about it; and, when a woman is being discussed, by treating her as an object - sexual or otherwise - but never a serious person with individual views. Of course, other forms of behavior in this society have the same purpose; but the phenomena seem especially clear linguistically.

The ultimate effect of these discrepancies is that women are systematically denied access to power, on the grounds that they are not capable of holding it as demonstrated by their linguistic behavior along with other aspects of their behavior; and the irony here is that women are made to feel that they deserve such treatment, because of inadequacies in their own intelligence and/or education. But in fact it is precisely because women have learned their lessons so well that they later suffer such discrimination."

${ }^{15}$ Trecho original: "Language casts sheaves of reality upon the social body, stamping it and violently molding it."
} 
77 , tradução $\left.\operatorname{minh}^{16}\right)$. No entanto, em outro ensaio sobre a linguagem, Wittig discute o fato de que, na língua, não existem dois gêneros linguisticamente delimitados. Segundo ela, o gênero masculino é considerado como genérico ou universal, e não é linguisticamente marcado; em contrapartida, o gênero feminino remete a um espaço semântico visto socialmente como particular e limitado, e deve necessariamente ser explicitado na língua. Desta forma, apenas o gênero feminino realiza-se na língua como uma distinção de fato existente (p. 60).

De forma interessante, Wittig observa, em um de seus ensaios, que o gênero se manifesta na língua através do sujeito do discurso, representado pelos pronomes pessoais. Segundo ela, as marcas de gênero são difundidas na língua pelo uso de pronomes pessoais, que "carregam" tais marcas de forma quase imperceptível. A escritora mantém que "assim que há um locutor no discurso, assim que há um 'Eu', o gênero se manifesta”, mas que, uma vez que é comum a noção de que o gênero no sujeito se restringe aos pronomes da terceira pessoa, "é como se o gênero não afetasse [os demais pronomes pessoais], não fosse parte de sua estrutura, mas apenas um detalhe em suas formas associadas" (1992, p. 79, tradução minha ${ }^{17}$ ). Wittig também argumenta que as manifestações do gênero podem ser mais bem observadas quando o sujeito do discurso pertence ao gênero feminino: de acordo com ela, membros do gênero feminino enquanto sujeitos do discurso devem obrigatoriamente especificar seu gênero de alguma forma; ou seja, membros do gênero feminino devem especificar e expressar sua posição social particularizada (não universalmente humana) e subordinada através do seu discurso. Sendo assim, pode-se supor que seria possível atribuir um gênero à autoria de um texto aparentemente "neutro", pois o sujeito do discurso carrega marcas de gênero que podem ser analisadas.

O sexo, sob o nome de gênero, permeia todo o corpo da língua e força todo locutor, se ele pertencer ao sexo oprimido, a proclamá-lo em sua fala, isto é, a aparecer na linguagem em sua forma física apropriada e não sob a forma abstrata, que todo locutor do gênero masculino possui o direito inquestionável de usar. (WITTIG, 1992, p. 79, tradução minha) ${ }^{18}$

\footnotetext{
${ }^{16}$ Trecho original: "[G]ender is the linguistic index of the political opposition between the sexes and of the domination of women."

${ }^{17}$ Trecho original: "Thus, it is as though gender does not affect them, is not a part of their structure, but only a detail in their associated forms. But, in reality, as soon as there is a locator in discourse, as soon as there is an 'I', gender manifests itself."

${ }^{18}$ Trecho original: "Sex, under the name of gender, permeates the whole body of language and forces every locutor, if she belongs to the oppressed sex, to proclaim it in her speech, that is, to appear in language under
} 


\section{PASSO A PASSO: O QUE FOI E COMO SE DEU O EXPERIMENTO}

O experimento em questão, como foi mencionado anteriormente, se deu através de uma pesquisa junto a 18 alunos de duas turmas diferentes de Inglês de nível PréIntermediário I no Celin. A fim de realizar o que se propôs fazer, alguns passos metodológicos foram seguidos. Selecionou-se um texto autêntico em inglês, retirado de um site da internet e no qual foram feitas ligeiras modificações com fim didático, porém sem alterar a estrutura textual e, portanto, levar a uma interpretação específica ${ }^{19}$. O texto em questão foi escolhido por dois motivos. Primeiramente, procurou-se por um texto que estivesse adequado à unidade temática que estava presentemente sendo trabalhada em sala de aula com os alunos, Work (trabalho, em inglês); seguindo-se tal critério, o texto selecionado foi uma exposição sobre um trabalho dos sonhos. Mas, principalmente, buscou-se um texto no qual não houvesse termos evidentes de especificação de gênero, que pudessem levar os alunos facilmente a uma interpretação quase unânime acerca do/a autor/a: o texto selecionado não possuía detalhes sobre a vida pessoal do/a autor/a, e a profissão dos sonhos mencionada no texto era a de jornalista freelancer - aparentemente neutra se comparada à profissão de professora de escola primária ou enfermeira, por exemplo, embora certamente não imune a interpretações baseadas em gênero ${ }^{20}$. Em sequência, elaborou-se uma atividade de leitura e compreensão baseada no texto selecionado, para ser aplicada nas duas turmas juntamente com um pequeno questionário de compreensão da autoria do texto selecionado ${ }^{21}$.

her proper physical form and not under the abstract form, which every male locutor has the unquestioned right to use."

${ }^{19}$ Definir a autenticidade de um texto em língua estrangeira é uma tarefa complexa, que não será abordada neste trabalho. No entanto, pode-se esclarecer que o texto utilizado para o experimento foi denominado autêntico pelo fato de que nele houve pouca alteração em termos léxico-estruturais, e as marcas estilísticas foram preservadas ao máximo. De fato, as alterações feitas no texto consistem na troca de três termos vocabulares e duas expressões por equivalentes próximos mais familiares aos alunos, além da ligeira correção de alguns problemas de pontuação.

${ }^{20}$ Como Penelope (1990) discute em seu livro, o gênero feminino é marcado na linguagem, sendo o gênero masculino tido como a norma; além disso, tudo que está relacionado ao gênero feminino é relegado à esfera privada da experiência humana, e, portanto, percebido como trivial e limitado em comparação à aparente universalidade presente na esfera pública, o espaço de domínio masculino. A observação de que a profissão de jornalista parece 'neutra', ou seja, não-marcada, aponta para o fato de que esta não é considerada estereotipicamente feminina, e que uma preponderância percentual de homens exercendo-a pode ser esperada.

${ }^{21} \mathrm{O}$ texto e o questionário estão em anexo. 
Este questionário era composto de três partes: a primeira para a identificação do sexo e turma dos alunos; a segunda para uma caracterização da personalidade do/a autor/a a partir de opções binárias; e a terceira para a identificação do gênero do autor com espaço de duas linhas para uma justificativa por escrito da escolha do aluno. Cada uma das partes integrantes do questionário foi formulada a partir de um propósito específico. O objetivo da primeira parte, na qual era esperado dos alunos que informassem o código identificador de sua turma e também seu sexo, era possibilitar o cruzamento desta última informação com a interpretação do gênero da autoria do texto, a fim de que uma relação entre os dois dados fosse estabelecida. Quanto à segunda parte, o objetivo principal era observar como os alunos fariam a caracterização da personalidade da pessoa que escreveu o texto, e analisar a relação entre tal caracterização e a interpretação do gênero da autoria. Nesta parte do questionário, que foi montada no formato de uma atividade do tipo "marque a(s) alternativa(s) correta(s)", os alunos poderiam assinalar características dentre as cinco opções binárias fornecidas: segurança/insegurança, controle de sua vida/falta de controle de sua vida, racionalidade/emotividade, expansividade/timidez, gosto por fazer muitas coisas/gosto por ficar em casa. Tais opções foram selecionadas a partir de concepções de gênero presentes no universo de discurso em que vivemos - "o homem é racional e seguro de si, e controla sua vida", "a mulher é insegura e emotiva, e possui menos controle de sua vida", etc. -, com os quais os alunos certamente possuíam familiaridade. Finalmente, a terceira parte do questionário tinha como propósito analisar a justificativa por escrito da interpretação dos alunos acerca do gênero da autoria do texto. É certo que, uma vez que as concepções de gênero são plenamente internalizadas por meio da socialização, a tarefa de expressar em palavras um julgamento praticamente intuitivo poderia se mostrar problemática; no entanto, em minha experiência em sala de aula verifiquei que a maioria dos alunos era plenamente capaz de apresentar um motivo para suas interpretações de gênero. Foi aplicada a atividade com o texto durante uma aula, e logo após a aplicação desta foi pedido aos alunos que preenchessem o questionário.

\section{ANÁLISE DOS DADOS: O QUE FOI REVELADO NO EXPERIMENTO}

A atividade com o texto escolhido e o questionário foram aplicados nos dias 16 e 18 de setembro de 2011, e os dados recolhidos foram representados em gráficos e 
analisados posteriormente. Partindo-se, como base teórica, das análises da língua feitas por Penelope, Wittig, Knutson e Lakoff, foi levantada a hipótese inicial de que, apesar da ausência de marcas evidentes de gênero no texto, os alunos seriam perfeitamente capazes de atribuir um gênero à autoria do texto, bem como o fariam de acordo com as concepções de gênero presentes no universo de discurso patriarcal, no qual estão inseridos. Pode-se dizer que os resultados corresponderam às expectativas iniciais em diversos aspectos.

Dentre os 18 alunos, a maioria era do sexo feminino - quinze ou $83 \%$ aproximadamente - e apenas três eram do sexo masculino. Dez alunos - ou pouco mais de $50 \%$ - interpretaram a autoria do texto como sendo feminina; ou seja, houve um certo equilíbrio entre as respostas. De forma interessante, cerca de $60 \%$ das alunas identificou a autoria como feminina; o mesmo fenômeno se observou entre os alunos de sexo masculino - dois dos três alunos identificaram o autor do texto como sendo um homem. Obviamente, entende-se que a amostra de dados utilizada neste estudo não é suficiente para que uma conclusão sólida seja traçada; no entanto, poderia ser formulada a hipótese de que parte dos alunos se identificou com o autor do texto, e relacionou o gênero da autoria com o seu próprio.

Quanto à caracterização do autor a partir de opções binárias no questionário, os resultados foram estereotípicos em três dos cinco aspectos observados. No aspecto controle sobre sua vida vs. falta de controle sobre sua vida, por exemplo, alunos que identificaram a autoria do texto como masculina caracterizaram o autor consideravelmente mais como possuindo controle de sua vida do que não o possuindo - 50\% contra $30 \%$; por sua vez, alunos que identificaram a autoria como feminina caracterizaram a autora igualmente como possuindo controle ou não sobre sua vida - 30\% para cada opção. É importante salientar que, partindo-se de uma análise textual, é possível construir argumentos para a caracterização do autor tanto como alguém que possui controle de sua vida como o contrário; porém, o que se observou nos dados é que as concepções de gênero que permeiam o universo patriarcal de discurso (que definem o homem como mais na posse de controle sobre sua vida do que a mulher) direcionaram as interpretações dos alunos. No aspecto emotividade vs. racionalidade, os resultados ficaram também dentro do esperado: alunos que identificaram a autoria como feminina definiram a autora como mais emotiva do que racional - 50\% contra $40 \%$; alunos que interpretaram a autoria como masculina caracterizaram o autor como mais racional do que emotivo - 37,5\% contra $25 \%$. Foi 
igualmente interessante notar que, no aspecto expansividade vs. timidez, a caracterização da pessoa que escreveu o texto como tímida foi relacionada apenas à autoria feminina (10\%); o/a autor/a do texto foi predominantemente caracterizado/a como uma pessoa expansiva, com variação pequena quanto à associação com autoria feminina ou masculina (70\% contra 75\%). O aspecto insegurança vs. segurança não apresentou diferenças percentuais grandes relacionadas à identificação do gênero da autoria - o/a autor/a foi caracterizado/a como uma pessoa mais insegura do que segura, com ligeira variação quanto à interpretação do gênero (20\% no caso de autoria feminina e $25 \%$ no caso de autoria masculina). Da mesma forma, o aspecto gosto por fazer muitas coisas apresentou diferenças percentuais pequenas relacionadas ao gênero da autoria $-70 \%$ para a autoria feminina e $75 \%$ para a masculina ${ }^{22}$.

Por final, quando se pediu no questionário que os alunos justificassem sua interpretação do gênero da autoria do texto, as respostas recebidas caíram novamente no âmbito das concepções de gênero. Dentre os alunos que interpretaram a autoria como feminina, $40 \%$ justificaram sua escolha a partir do aspecto da emotividade, sensibilidade ou sinceridade; $20 \%$ a partir da indecisão ou do grande esforço para fazer-se uma escolha; $20 \%$ a partir dos aspectos combinados de expansividade, confiança e também o desejo de realizar um sonho; $10 \%$ a partir do aspecto do idealismo e pouca praticidade, e $10 \%$ a partir do aspecto da dependência da opinião de outros para tomar-se uma decisão. Dentre os alunos que perceberam a autoria como masculina, 25\% justificaram a partir do aspecto da certeza acerca dos objetivos ou do planejamento do futuro; $12,5 \%$ a partir do aspecto da racionalidade; $12,5 \%$ a partir do aspecto da predominância masculina na profissão desejada pelo autor; $12,5 \%$ a partir do aspecto da irresponsabilidade ou descaso demonstrada pelo autor; $12,5 \%$ afirmaram não saber justificar. De forma interessante, $25 \%$ apresentaram

\footnotetext{
${ }^{22}$ Quanto às pequenas diferenças percentuais de interpretação de gênero mencionadas na análise da segunda parte dos questionários, é importante salientar que seria necessário um estudo estatístico mais aprofundado para averiguar se tais porcentagens aparentemente "pequenas" são relevantes à análise - o que não será possível fazer neste trabalho. Porém, pode-se formular a hipótese de que as diferenças percentuais observadas na correlação entre a atribuição dos aspectos insegurança, gosto por fazer muitas coisas e expansividade e a interpretação do gênero da autoria possuem, sim, relevância. Por exemplo, a diferença percentual observada no aspecto insegurança poderia apontar para uma atribuição um pouco maior desta qualidade à autoria masculina, o que iria contra a noção socialmente difundida de que membros do gênero masculino são menos inseguros do que membros do gênero feminino; de maneira inversa, a diferença percentual observada no aspecto gosto por fazer muitas coisas poderia expressar uma atribuição um pouco maior desta qualidade à autoria masculina, o que confirmaria a noção socialmente difundida de que membros do gênero masculino são mais ativos e corroboraria a análise de Penelope (1990) sobre a identificação da esfera pública - onde "muitas coisas" são feitas - como domínio dos homens.
} 
como justificativa a leitura do termo freshman (calouro/a, em inglês) como um termo especificador de gênero. De fato, ele é um termo masculino, que talvez remeta ao longo período histórico - documentado por pesquisadoras como Marilyn French (1986) - no qual apenas homens possuíam acesso à educação superior; porém, conforme observa Penelope (1988), uma vez que o universo de discurso patriarcal coloca o homem como o representante do ser humano como um todo, termos masculinos (como freshman) são então considerados "universais" ou "neutros", nos quais a inclusão do gênero feminino não se dá através de uma inferência concreta, mas sim de uma mera pressuposição (p. 122).

É importante salientar que todas as justificativas apresentadas pelos alunos são afirmações correntes no universo de discurso patriarcal acerca do comportamento "normal" de membros do gênero feminino e masculino: segundo o estereótipo sexual, as mulheres são inseguras, emotivas, idealistas e dependentes; os homens, por sua vez, são confiantes, racionais, práticos e independentes. Uma vez que tais concepções são amplamente difundidas e internalizadas pelos membros da sociedade, os alunos não hesitaram em utilizar-se delas para justificar sua escolha do gênero da autoria do texto. Com isso, os alunos acabaram por construir um julgamento de valor acerca da personalidade do/a autor/a do texto, considerando esta pessoa como mais ou menos confiável, mais ou menos responsável ou séria - dependendo do gênero atribuído à autoria - o que certamente alterava a sua relação com o texto. Seria interessante analisar a formação desses julgamentos de valor mais a fundo. Mas, analisando-se apenas os resultados apresentados, poderia surgir a pergunta: como lidar com o gênero em sala de aula? Como é possível trabalhar junto aos alunos com o objetivo de levá-los a refletir sobre as concepções de gênero difundidas em nosso universo de discurso? É evidente que a resposta não é simples. A fim de motivar a conscientização dos alunos acerca de algo tão profundamente internalizado e pouco refletido, é necessário um trabalho bem estruturado com uma metodologia precisa. Entretanto, por falta de espaço e oportunidade, este artigo propõe não uma solução, mas uma pergunta - que poderia, futuramente, motivar a busca por respostas na forma de estratégias e metodologias de trabalho. 


\section{CONCLUSÃO}

Como visto anteriormente, diversas pesquisadoras consideram a língua como um código não-neutro, no qual as visões de mundo que permeiam a sociedade estão impregnadas. Como sustentado por Penelope, por exemplo, o gênero na língua é um reflexo das concepções de gênero que fazem parte do universo de discurso patriarcal, e suas manifestações na língua podem ser observadas tanto ao nível semântico-lexical quanto ao nível fonológico, morfológico e sintático. Além disso, Penelope, Wittig e Lakoff também argumentam que o gênero feminino é marcado na língua, sendo necessária a sua especificação linguística. Sendo assim, é plenamente realista esperar que as concepções de gênero exerçam influência considerável sobre a interpretação do gênero da autoria de um texto, "neutro" ou não.

Foi possível verificar, por meio do experimento, que os alunos interpretaram e justificaram o gênero da autoria predominantemente com base em concepções de gênero. Como observado na análise dos dados recolhidos, a atribuição do gênero feminino à autoria do texto se baseou consideravelmente no fator da emotividade e indecisão; a atribuição do gênero masculino se baseou em boa parte no fator da racionalidade e controle sobre a própria vida. É possível concluir através da análise dos dados que as concepções de gênero provenientes do universo de discurso patriarcal determinam em muito a compreensão dos leitores de um texto acerca do gênero da autoria. E, mesmo que não haja termos especificadores de gênero evidentes, os leitores são capazes de atribuir a autoria a um dos gêneros, utilizando como ferramenta a aplicação das concepções de gênero que constituem o universo de discurso patriarcal. Devido ao uso das concepções de gênero, os alunos construíram um julgamento de valor acerca do/a autor/a, alterando a relação estabelecida com o texto. Porém, como comentado anteriormente, decidiu-se não levantar estratégias possíveis para trabalhar com a conscientização dos alunos acerca das concepções de gênero, a fim de evitar uma discussão por demais breve e ineficaz no pequeno espaço restante neste artigo. De qualquer maneira, espera-se que, em um momento futuro, a pergunta apresentada neste artigo leve a uma discussão proveitosa de possíveis respostas.

\section{REFERÊNCIAS}


FRENCH, Marilyn. Beyond Power: On Women, Men and Morals. Londres: Abacus, 1986.

FRYE, Marilyn. Sexism. In: The Politics of Reality: essays in feminist theory. Berkeley: Crossing Press, 1983, p. 17-39.

JEFFREYS, Sheila. Unpacking Queer Politics. Cambridge: Polity/Blackwell, 2003.

JORDÃO, Clarissa. M. As lentes do discurso: letramento e criticidade no mundo digital. Trabalhos em Linguística Aplicada, Campinas, 46(1), p. 19-29, Jan./Jun. 2007.

LAKOFF, Robin. Language and Woman's Place. Language in Society, Cambridge, v. 2, n. 1 , p. 45-80, abr.1973.

KNUTSON, Susan. Challenging the Masculine Generic. Tessera, Quebec, v. 4, p. 76-88, verão 1988.

PENELOPE [STANLEY], Julia. Speaking Freely: Unlearning the Lies of the Fathers' Tongues. New York: Teachers College Press, 1990.

Prescribed Passivity: The Language of Sexism. In: A Feminist Ethic For Social Science Research. Lewiston/Queenston: Edwin Mellen, 1988, p. 119-138.

THOMPSON, Denise. Radical Feminism Today. London: Sage, 2001.

WILKINSON, Sue; KITZINGER, Celia. The Queer Backlash. In: BELL, Diane; KLEIN, Renate (ed.). Radically Speaking: Feminism Reclaimed. Melbourne: Spinifex, 1997.

WITTIG, Monique. The Category of Sex. In: The Straight Mind and Other Essays. Boston: Beacon, 1992, p. 1-8.

. The Mark of Gender. In: The Straight Mind and Other Essays. Boston: Beacon, 1992, p. 76-89.

The Point of View: Universal or Particular? In: The Straight Mind and Other Essays. Boston: Beacon, 1992, p. 59-67. 


\section{ANEXO: TEXTO, QUESTIONÁRIO, GRÁFICOS E TABELA}

\section{My Dream Job}

A dream job to me is a job you can go to everyday and never get tired of it, I am not completely sure about what that means to me at this point in my life. I have a few ideas of what could be my dream job so I guess I'll pick one. One of my possibilities of a dream job is a freelance journalist. The reason I think this is a dream job is because I love to travel and I love to write, a freelance journalist gets to combine those two things so for me it's a win-win situation. Freelance journalists travel around the country and sometimes even around the world writing stories about events or people in the places they travel to. This is my first choice for a dream job, but of course I have a few backups.

I have never been a freelance journalist and I don't know anyone who is one, so I'm not completely sure what I have to do to get where I need to be to have this dream job. I know I need to take Mass Communication classes and specific courses dealing with journalism. I hope that studying will help with that. I also know I can help myself out by working with the various journalistic groups we have on campus. There is a radio station and TV station that I could get involved with and I'm sure there is a newspaper I could write for. I know I could probably find an internship around here that would help me out. All of these things are what I need to do to get to where I want to be.

I agree with my friend Alex that you should start working while you are still a freshman to put things on your resume. It will give you much more experience and experience always looks good for a job. Also, the more experience you have under your belt, the more comfortable you are going into a job. Anyway, it is a good thing for your resume and for your personal work experience.

Adaptado de: http://wordpress.morningside.edu/tms011/2011/09/14/my-dream-job-3/

\section{Questionnaire}

Schedule:

Sex: ( ) Female ( ) Male

In my opinion, the author of the text I have just read is:

( ) confident

( ) insecure 
( ) in control of his/her life (or trying to be in control)

( ) not exactly in control of his/her life

( ) a talkative person

( ) a shy (or more introverted) person

( ) someone who is or tries to be rational

( ) someone who is more emotional

( ) someone who likes to do many things

( ) someone who likes to stay home

I think that the author is

( ) a woman ( ) a man

because:
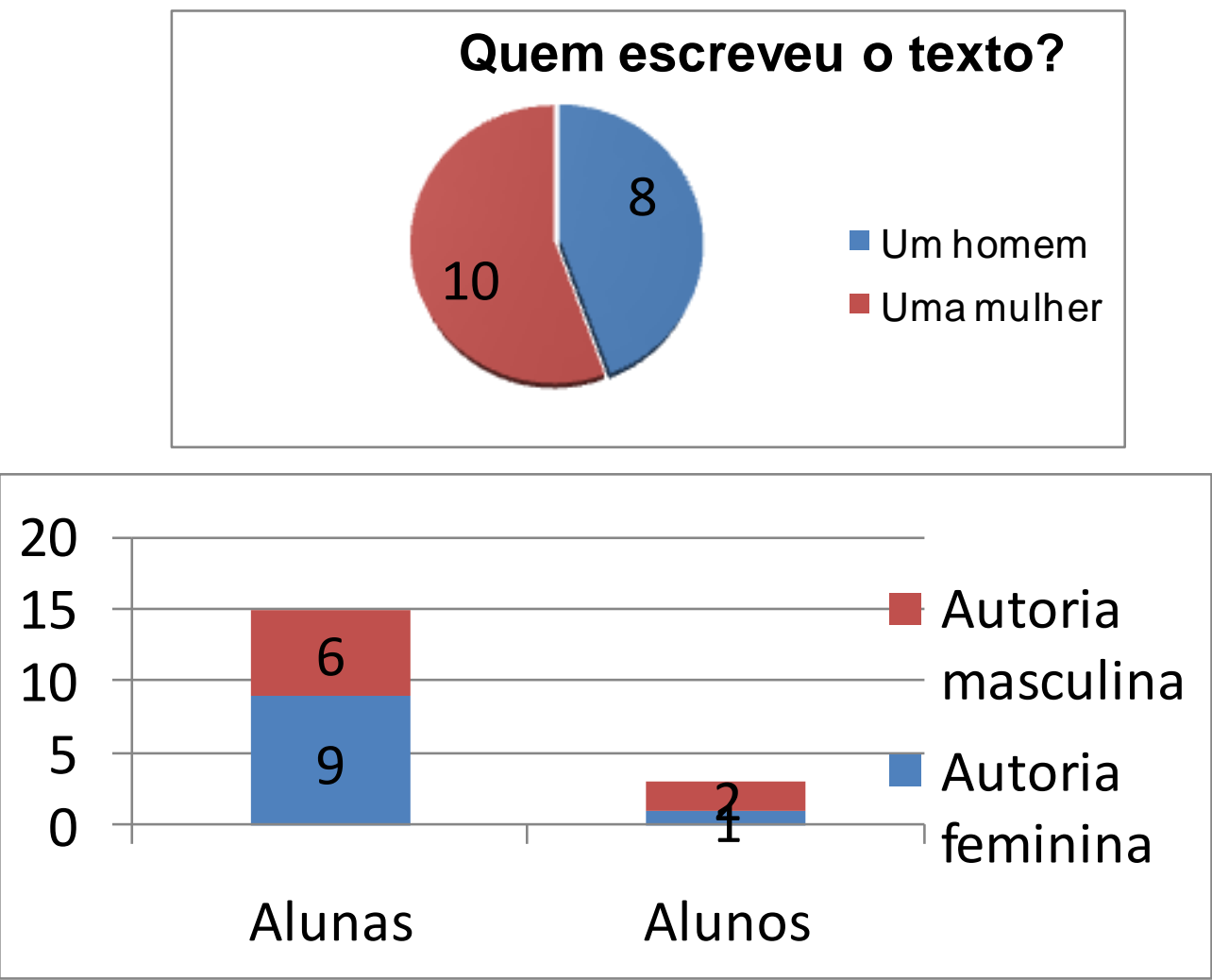


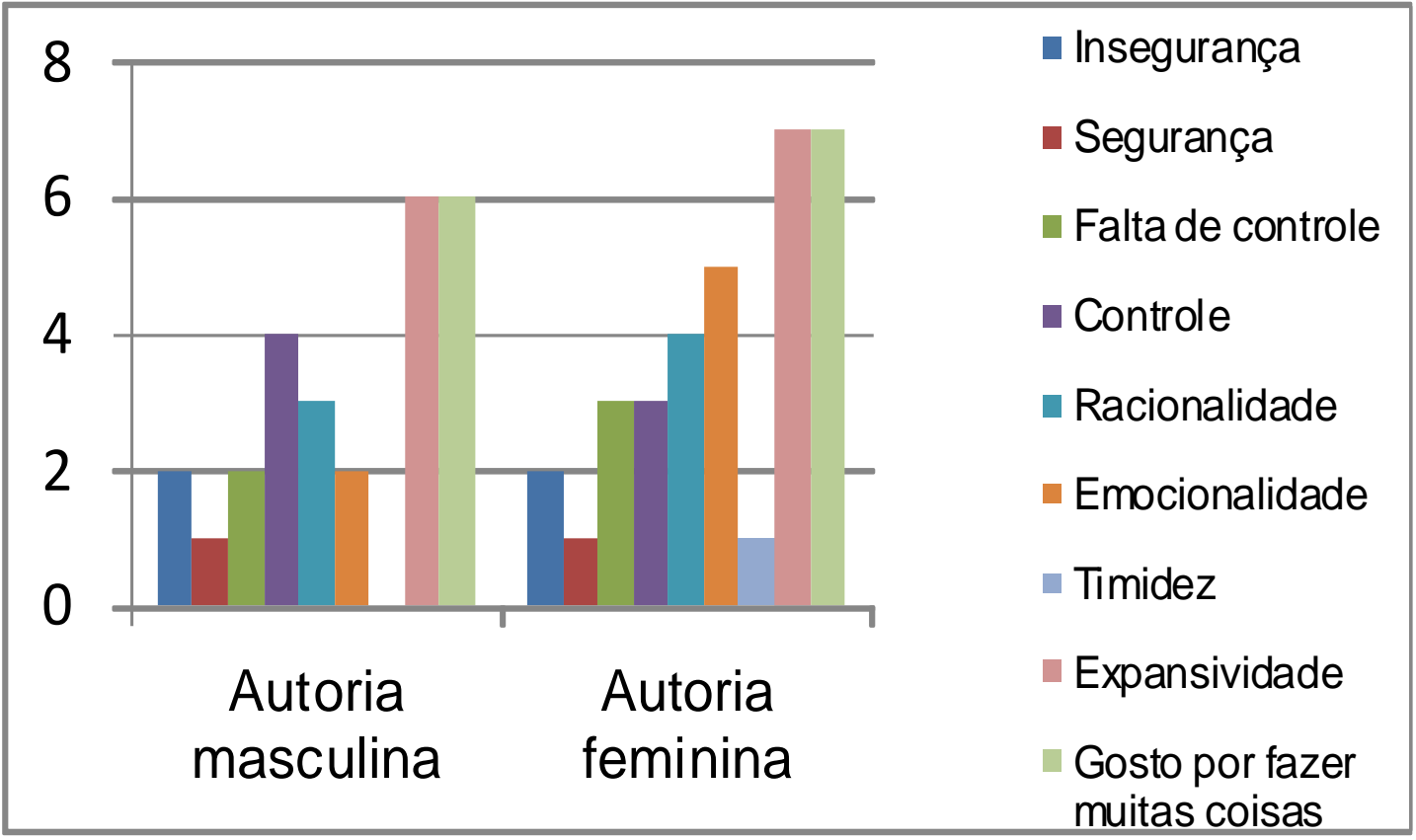

\begin{tabular}{|l|c|c|}
\hline & Autoria Feminina & Autoria Masculina \\
\hline Insegurança & $20 \%$ & $25 \%$ \\
\hline Segurança & $10 \%$ & $12,5 \%$ \\
\hline Controle & $30 \%$ & $50 \%$ \\
\hline Falta de controle & $30 \%$ & $25 \%$ \\
\hline Emotividade & $50 \%$ & $25 \%$ \\
\hline Racionalidade & $40 \%$ & $37,5 \%$ \\
\hline Expansividade & $70 \%$ & $75 \%$ \\
\hline Timidez & $10 \%$ & $0 \%$ \\
\hline Gosto por fazer muitas coisas & $70 \%$ & $75 \%$ \\
\hline
\end{tabular}



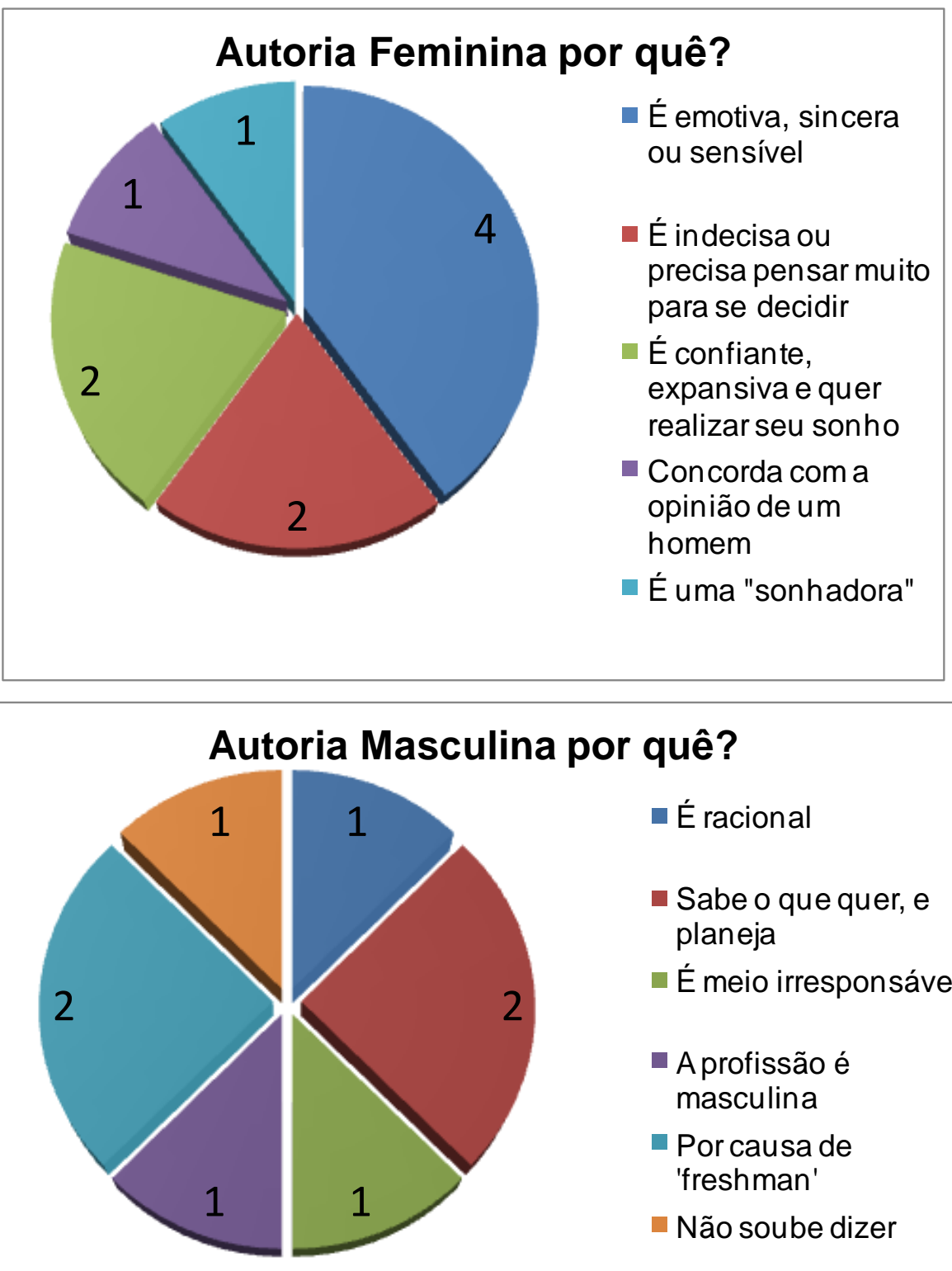

- É racional

- Sabe o que quer, e planeja

- É meio irresponsável

- A profissão é masculina

- Por causa de 'freshman'

- Não soube dizer 